\title{
Decontamination of a Contaminated RCP Shaft Using the SP-HyBRID Process
}

\author{
Hee-Chul Eun ${ }^{1,2, *}$, Na-On Chang ${ }^{3}$, Wang-Kyu Choi ${ }^{1}$, Sang-Yoon Park ${ }^{1}$, Seon-Byeong Kim ${ }^{1}$, Bum-Kyoung Seo ${ }^{1}$, \\ Ki-Chul Kim ${ }^{4}$ and Seung-Geon An ${ }^{5}$ \\ 1 Decommissioning Technology Research Division, Korea Atomic Energy Research Institute, \\ Daedeok-daero 989-111, Yuseong-gu, Daejeon 34057, Korea; wkchoi@kaeri.re.kr (W.-K.C.); \\ sypark@kaeri.re.kr (S.-Y.P.); sbkim@kaeri.re.kr (S.-B.K.); bum@kaeri.re.kr (B.-K.S.) \\ 2 Quantum Energy Chemical Engineering, University of Science and Technology, Gajeong-ro 217, Yuseong-gu, \\ Daejeon 34113, Korea \\ 3 Department of Nuclear Engineering, Hanyang University, Wangsimni-ro 222, Seongdong-gu, \\ Seoul 04763, Korea; nochang@hanyang.ac.kr \\ 4 Nuclear Power Maintenance Engineering Center, KEPCO KPS, Munsan2Sandan1-ro 69-46, Oedong-eup, \\ Gyeongju 38206, Korea; kc@kps.co.kr \\ 5 Sunkwang T\&S, Gongwon-ro 3, Guro-gu, Seoul 08298, Korea; sga@sunkwang.com \\ * Correspondence: ehc2004@kaeri.re.kr
}

check for updates

Citation: Eun, H.-C.; Chang, N.-O.; Choi, W.-K.; Park, S.-Y.; Kim, S.-B.; Seo, B.-K.; Kim, K.-C.; An, S.-G. Decontamination of a Contaminated RCP Shaft Using the SP-HyBRID Process. Processes 2021, 9, 1725. https://doi.org/10.3390/pr9101725

Academic Editor: George Z. Kyzas

Received: 4 July 2021

Accepted: 22 September 2021

Published: 26 September 2021

Publisher's Note: MDPI stays neutral with regard to jurisdictional claims in published maps and institutional affiliations.

Copyright: (c) 2021 by the authors. Licensee MDPI, Basel, Switzerland. This article is an open access article distributed under the terms and conditions of the Creative Commons Attribution (CC BY) license (https:/ / creativecommons.org/licenses/by/ $4.0 /)$.

\begin{abstract}
It is very important to minimize the waste generation for decontamination of the reactor coolant system in a nuclear facility. As an alternative to commercial decontamination technologies, an inorganic acid chemical decontamination (SP-HyBRID) process can be effectively applied to the decontamination because it can significantly reduce the waste generation. In this study, the decontamination of a contaminated reactor coolant pump shaft from a nuclear facility was conducted using the SP-HyBRID process. First, equipment for a mock-up test of the decontamination was prepared. Detailed experimental conditions for the decontamination were determined through the mock-up test. Under the detailed conditions, the contaminated shaft was successfully decontaminated. The dose rate on the shaft surface was greatly reduced from 1400 to $0.9 \mu \mathrm{Sv} / \mathrm{h}$, and the decontamination factor showed a very high value (>1500).
\end{abstract}

Keywords: decontamination; nuclear facility; SP-HyBRID process; a contaminated RCP shaft; decontamination factor

\section{Introduction}

A corrosion oxide layer containing radioactive nuclides is deposited in the RCS (reactor coolant system) in a nuclear facility operated at a high temperature and a high pressure [1-4]. This corrosion oxide layer generates radiation build-up, and this can increase the risk of radiation exposure to workers [3-6]. It thus must be removed from the RCS. A chemical decontamination process can be effectively utilized to decontaminate the layer [6-11]. The HP CORD UV (Permanganic acid Chemical Oxidation Reduction Decontamination based on the acid permanganate Ultra-Violet light) process using an organic acid is widely used as a representative chemical decontamination process because it has a high decontamination factor (DF), and it has a problem that a considerable amount of radioactive ion exchange resin is generated as a secondary waste [9-11].

To resolve this problem, KAERI (Korea Atomic Energy Research Institute) has been developing the SP-HyBRID (Sulfuric acid Permanganate Hydrazine Based Reductive metal Ion Decontamination) process, a chemical decontamination process using inorganic chemicals, as diagrammed in Figure $1[12,13] . \mathrm{H}_{2} \mathrm{SO}_{4}$ and $\mathrm{KMnO}_{4}$ are used as decontamination reagents in the oxidative process, and the chemical reagents used in the HyBRID process are $\mathrm{N}_{2} \mathrm{H}_{4}, \mathrm{H}_{2} \mathrm{SO}_{4}$, and $\mathrm{CuSO}_{4}$. Cr-rich oxides are dissolved in the oxidative process, and Fe-rich oxides are dissolved in the reductive process [12,14]. In the SP-HyBRID process, the 
wastewater is purified by a precipitation method using $\mathrm{Ba}(\mathrm{OH})_{2}$, and a filtration method. Finally, $\mathrm{BaSO}_{4}$ waste containing metal hydroxides is generated, and the use of ion exchange resin is very minor $[14,15]$. For this reason, the SP-HyBRID process thus can significantly reduce the secondary waste generation when compared with the HP CORD UV process. However, it is necessary to demonstrate the performance of the SP-HyBRID process for application to nuclear facilities.

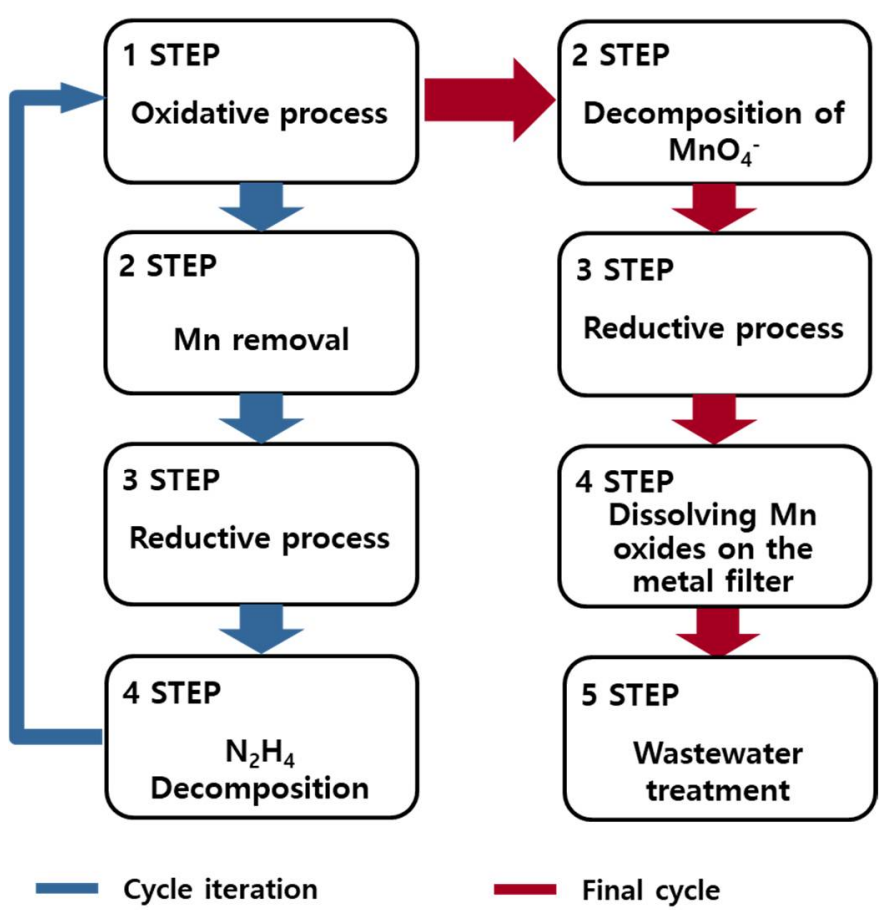

Figure 1. Flow diagram of the SP-HyBRID process.

In this study, a decontamination test of a contaminated RCP (reactor coolant pump) shaft from a nuclear facility was conducted using the SP-HyBRID process. Based on the results of this test, the performance of the process was evaluated.

\section{Experimental and Methods}

\subsection{Materials}

The SS 304 specimens $(50 \times 50 \times 2 \mathrm{~mm})$ with a simulated corrosion oxide layer were prepared for a mock-up test of the decontamination test, as shown in Figure 2. The specimens were manufactured using an acidic solution in an autoclave (Ilshin autoclave, Daejeon, Republic of Korea, ISA-BC-0100-SS-20-315-SYS). The acidic solution was composed of 0.1 M EDTA-2Na (Junsei, 99.5\%) and 0.1 M EDTA (Junsei, 99.5\%). The autoclave was operated at $250{ }^{\circ} \mathrm{C}$ for $96 \mathrm{~h}$. The simulated oxide layer was identified as magnetite $\left(\mathrm{Fe}_{3} \mathrm{O}_{4}\right)$ by means of XRD analysis, as shown in Figure 3.

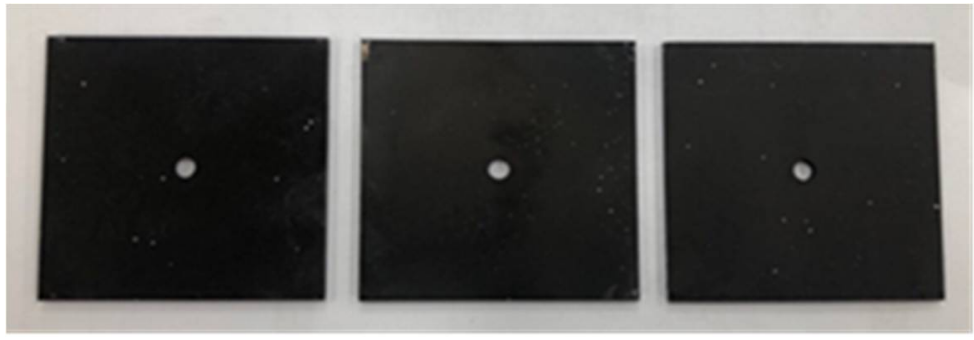

Figure 2. SS 304 specimens with a simulated corrosion oxide layer. 


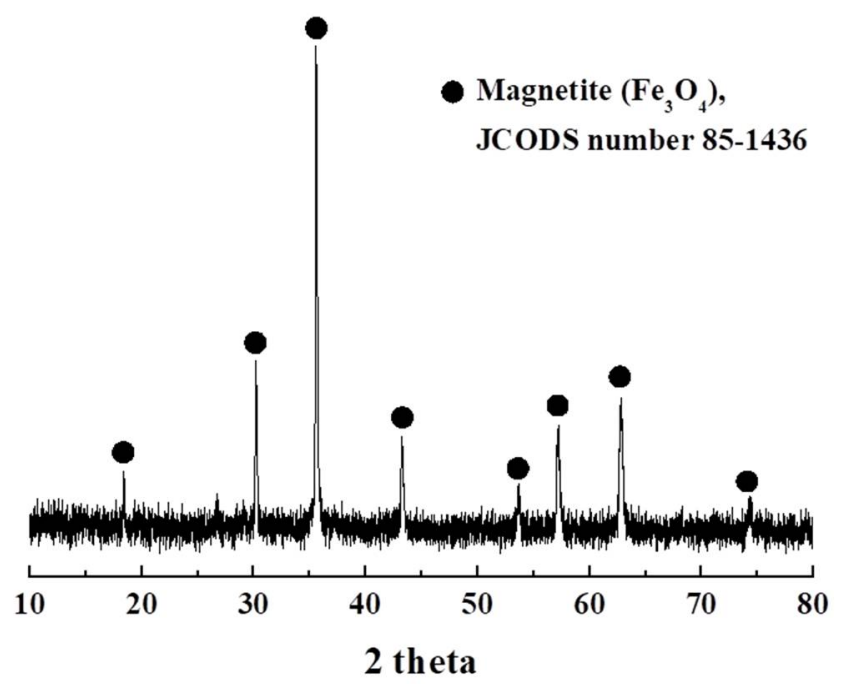

Figure 3. XRD-patterns of the simulated corrosion oxide layer on the specimens.

A contaminated RCP shaft was obtained from a nuclear power plant in Korea, and it is shown in Figure 4. This shaft is composed of a stainless steel material. The total length of the shaft is about $2.3 \mathrm{~m}$. The area red-lined in Figure 4 is directly connected with the RCS as a contaminated area. The contact dose rate of spot A in Figure 4 was measured using a teletector radiation detector (Automess, Ladenburg, Germany, 6150ADT, energy range: $65 \mathrm{keV} \sim 1.3 \mathrm{MeV}$, dose rate range: $0.01 \mu \mathrm{Sv} / \mathrm{h} \sim 9.99 \mathrm{~Sv} / \mathrm{h}$ ), and it was about $1400 \mu \mathrm{Sv} / \mathrm{h}$ as the average of three measurements.

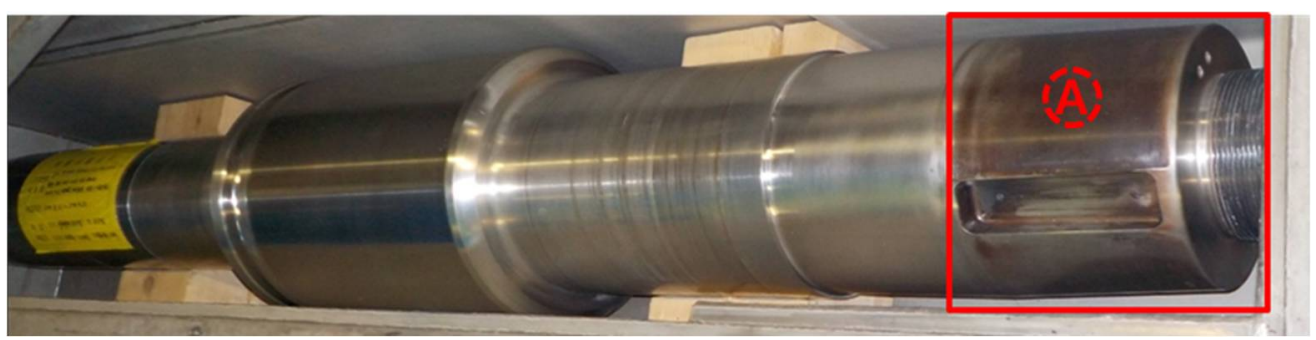

Figure 4. Contaminated RCP shaft from a nuclear plant.

In the decontamination test, $\mathrm{H}_{2} \mathrm{SO}_{4}$ (Showa, $97 \%$ ), $\mathrm{KMnO}_{4}$ (Daejung, 99.3\%), $\mathrm{N}_{2} \mathrm{H}_{4} \cdot \mathrm{H}_{2} \mathrm{O}$ (Junsei, $98 \%$ ), $\mathrm{CuSO}_{4}$ (Junsei, 97.5\%), and $\mathrm{H}_{2} \mathrm{O}_{2}$ (Daejung, 35\%) were used as decontamination reagents, and their concentrations are provided in Table 1.

\subsection{Experimental}

Equipment was prepared to conduct the decontamination test of the contaminated shaft, as shown in Figure 5 [13]. The equipment has a capacity of $30 \mathrm{~L}$ scale based on the SP-HyBRID decontamination solution, and it consists of a decontamination reactor, a circulation system, and a decontamination wastewater treatment system. The decontamination reactor ( $15 \mathrm{~L}$ based on the decontamination solution) was designed to accommodate the contaminated RCP shaft, and it contained a mockup of the RCP shaft head, as shown in Figure 5. The simulated specimens can be mounted on the mockup. The circulation system circulates a decontamination solution, and it consists of an injector, a buffer tank, a heater, a circulation pump, a chiller, a monitor, and a metal filter. The injector supplies a constant amount of decontamination reagents using a metering pump. The buffer tank accommodates a decontamination solution, and it has a capacity of $45 \mathrm{~L}$. It also contains a condenser and a charcoal filter to minimize the evaporation of the decontamination solution and prevent the emissions of air pollutants. The heater heats a decontamination solution by an operation temperature. It is possible for the circulation pump to adjust the flow rates by $45 \mathrm{~L} / \mathrm{min}$ using an inverter control system. The chiller reduces a decontamination solution 
with a high temperature $\left(90 \sim 95{ }^{\circ} \mathrm{C}\right)$ to a temperature below $30^{\circ} \mathrm{C}$ to measure the $\mathrm{pH}$ of the decontamination solution. The monitor observes the $\mathrm{pH}$ of the decontamination solution in real time. The metal filter collects insoluble particles generated from the conversion of $\mathrm{MnO}_{4}{ }^{-}$into an oxide form. Finally, the decontamination wastewater treatment system consists of a reactor, a circulation pump, and a filter. The reactor conducts precipitation and decomposition reactions in the decontamination wastewater, and it contains a metering pump to inject chemical reagents. The circulation pump is a diaphragm type, and it is used to mix the decontamination wastewater in the reactor and transfer it to the filter. The filter separates insoluble particles from the decontamination wastewater after the precipitation and decomposition reactions.

Table 1. Concentrations of chemical reagents used in this study.

\begin{tabular}{|c|c|c|c|}
\hline Cycle & Step & Chemical Reagent & Concentration $[\mathrm{mM}]$ \\
\hline \multirow{4}{*}{$\begin{array}{l}\text { Iterated cycle } \\
\qquad(1 s t, 2 \text { nd })\end{array}$} & SP oxidative process & $\begin{array}{c}\mathrm{H}_{2} \mathrm{SO}_{4} \\
\mathrm{KMnO}_{4}\end{array}$ & $\begin{array}{c}0 \sim 3.25 \\
6.33\end{array}$ \\
\hline & Removal process of Mn & $\mathrm{N}_{2} \mathrm{H}_{4}$ & $5 \sim 6.00$ \\
\hline & HyBRID reductive process & $\begin{array}{c}\mathrm{H}_{2} \mathrm{SO}_{4} \\
\mathrm{~N}_{2} \mathrm{H}_{4} \\
\mathrm{CuSO}_{4}\end{array}$ & $\begin{array}{c}25 \sim 30.00 \\
50.00 \\
0 \sim 0.50\end{array}$ \\
\hline & $\begin{array}{l}\text { Decontamination process of } \\
\text { hydrazine }\left(\mathrm{N}_{2} \mathrm{H}_{4}\right)\end{array}$ & $\mathrm{H}_{2} \mathrm{O}_{2}$ & $125 \sim 150.00$ \\
\hline \multirow{4}{*}{$3 \mathrm{rd}$} & SP oxidative process & $\begin{array}{l}\mathrm{H}_{2} \mathrm{SO}_{4} \\
\mathrm{KMnO}_{4}\end{array}$ & $\overline{6.33}$ \\
\hline & Decomposition process of $\mathrm{MnO}_{4}^{-}$ & $\mathrm{N}_{2} \mathrm{H}_{4}$ & 7.91 \\
\hline & HyBRID reductive process & $\begin{array}{c}\mathrm{H}_{2} \mathrm{SO}_{4} \\
\mathrm{~N}_{2} \mathrm{H}_{4} \\
\mathrm{CuSO}_{4}\end{array}$ & $\begin{array}{c}25 \sim 30.00 \\
50.00 \\
-\end{array}$ \\
\hline & $\begin{array}{l}\text { Dissolution process of Mn oxides on } \\
\text { the filter (filter cleaning) }\end{array}$ & - & - \\
\hline
\end{tabular}

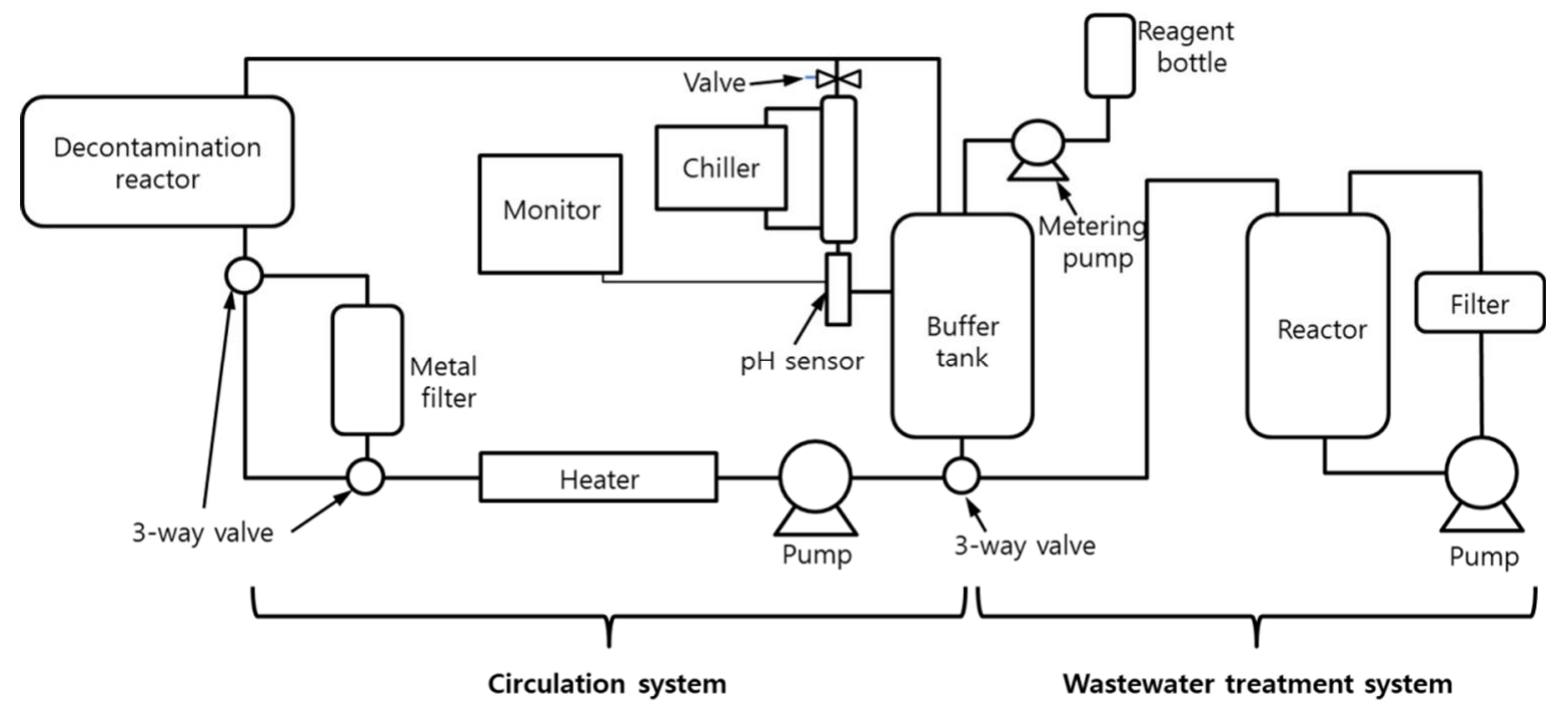

Figure 5. Diagram of equipment used for the decontamination test of a contaminated RCP shaft.

\subsection{Decontamination Test}

A mock-up test of the RCP shaft decontamination was conducted as follows. First, three simulated specimens were mounted on the RCP shaft mockup, and the decontamination reactor was sealed. Next, $30 \mathrm{~L}$ of deionized (DI) water was charged into the buffer 
tank and then circulated and heated in the decontamination reactor and the circulation system. After the temperature of the DI water reached $90{ }^{\circ} \mathrm{C}$, chemical reagents used in the oxidative process were injected into the buffer tank, and the oxidative process was conducted for a constant time. $\mathrm{N}_{2} \mathrm{H}_{4}$ was then injected into the oxidative process solution for the Mn removal process while circulating the solution to the loop containing the metal filter. After finishing the Mn removal process, chemical reagents used in the reductive process were injected into the buffer tank, and the reductive process was conducted for a constant time. At this time, the metal filter was not incorporated in the circulation loop of the reductive process solution. Lastly, the decomposition of $\mathrm{N}_{2} \mathrm{H}_{4}$ in the reductive process solution was conducted using $\mathrm{H}_{2} \mathrm{O}_{2}$. These processes became one cycle. This cycle is an iterated cycle, as shown in Table 1, and it was conducted two times in the mock-up test. In the 3rd cycle shown in Table 1, the decomposition process of $\mathrm{MnO}_{4}{ }^{-}$was conducted after the oxidative process, and Mn oxides collected on the metal filter were dissolved using the reductive process solution after the 3 rd cycle reductive process. The operation times for the mock-up test are presented in Table 2.

Table 2. Operating time for the mock-up and decontamination test [h].

\begin{tabular}{ccccccc}
\hline \multirow{2}{*}{ Operation Step } & \multicolumn{2}{c}{ 1st Cycle } & \multicolumn{2}{c}{ 2nd Cycle } & \multicolumn{2}{c}{ 3rd Cycle } \\
\cline { 2 - 7 } & OP $^{\mathbf{1}}$ & $\mathbf{R P}^{\mathbf{2}}$ & OP & RP & OP & RP \\
\hline Mock-up test & 4 & 6 & 3 & 5 & 2 & 4 \\
Decontamination test & 10 & 6 & 8 & 4 & 6 & 4 \\
\hline
\end{tabular}

${ }^{1}$ OP: oxidative process, ${ }^{2}$ RP: reductive process.

The decontamination test of the contaminated RCP shaft was carried out following same procedures as the mock-up test, and the contaminated shaft head was loaded into the decontamination reactor instead of the RCP shaft mockup. The operation times for the decontamination test were scheduled based on the results of the mock-up test, and they are given in Table 2.

\subsection{Analysis}

The simulated oxide layer was characterized using an XRD (Bruker, Billerica, USA, D8 Advance A25, Conditions: $\mathrm{Cu}$ target, $\left.40 \mathrm{kV}, 40 \mathrm{~mA}, 0.2^{\circ} / \mathrm{s}\right)$. The $\mathrm{pH}$ of samples was observed using a measuring device (Thermo Fisher Scientific, Waltham, USA, Orion STARA2115), and concentrations of $\mathrm{N}_{2} \mathrm{H}_{4}$ in a sample were analyzed using UV-VIS spectroscopy (Hach, Billerica, USA, DR5000). Concentrations of metal ions in samples from the mock-up test were measured using an ICP-OES (Analytikjena, PQ 9000). Concentrations of radioactive nuclides in samples from the decontamination test were analyzed using an HPGe detector (Ametek Ortec, Oak Ridge, USA, GEM-C7080P4). The samples were collected twice after the unit process in each cycle.

\section{Results and Discussion}

\subsection{Decontamination of the Specimens Mounted on the Mockup of the RCP Shaft}

Before conducting the decontamination of the contaminated RCP shaft, a mock-up test of the decontamination was carried out using the specimens mounted on the mockup of the RCP shaft shown in Figure 5. As shown in Figure 4, the surface of the red-lined area was the mainly contaminated area in the RCP shaft. The decontamination results of the specimens mounted on the mockup thus can be used to determine detailed operation conditions for the RCP shaft decontamination.

The $\mathrm{pH}$ of the process solution is an important indicator for the decontamination process $[12,13,15]$. Thus, it is necessary to monitor it in real time during the decontamination process. In the SP-HyBRID process, the oxidative process is effective at a process solution $\mathrm{pH}$ below 2.3, and the $\mathrm{pH}$ of the reductive process solution is proper in a range of 2.5-3.0 [12]. These $\mathrm{pH}$ conditions can be changed with dissolution of the corrosion ox- 
ide layer during the decontamination process. If the changed $\mathrm{pH}$ deviates from the $\mathrm{pH}$ conditions, it must be adjusted using $\mathrm{H}_{2} \mathrm{SO}_{4}$ or $\mathrm{N}_{2} \mathrm{H}_{4}$. Figure 6 shows the $\mathrm{pH}$ changes in each unit process solution during the mock-up test. It is found that the mock-up test was conducted in the proper $\mathrm{pH}$ conditions. The $\mathrm{pH}$ of the 2 nd and 3rd oxidative process solutions showed lower values when compared to the $\mathrm{pH}$ of the 1st oxidative process solution. After the 1st and 2nd reductive process, the reductive reagent $\left(\mathrm{N}_{2} \mathrm{H}_{4}\right)$ in the process solution was decomposed by injecting $\mathrm{H}_{2} \mathrm{O}_{2}$ (weak acid). For this reason, the $\mathrm{pH}$ of the 2nd and 3rd oxidative process solutions were decreased. These decreases of $\mathrm{pH}$ reduced the use of $\mathrm{H}_{2} \mathrm{SO}_{4}$. It is also believed that the decreased $\mathrm{pH}$ can contribute to improving the effect of the oxidative process as a pretreatment process.

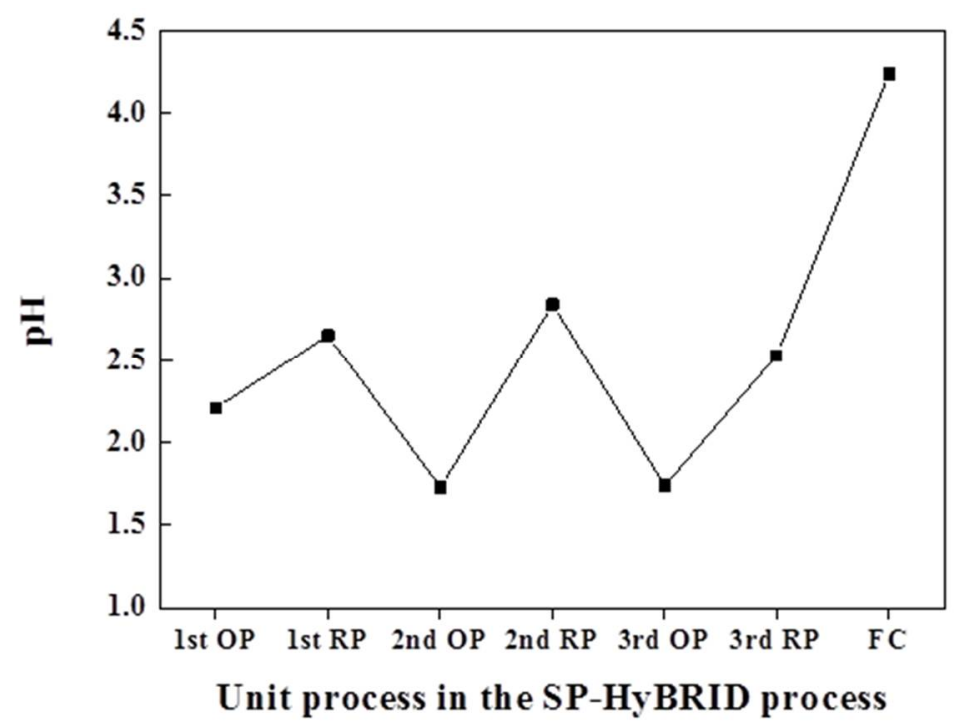

Figure 6. $\mathrm{pH}$ changes in each unit process solution during the mock-up test (OP: oxidative process, RP: reductive process, FC: filter cleaning).

The Mn removal and $\mathrm{N}_{2} \mathrm{H}_{4}$ decomposition in Figure 1 are processes to decompose or remove the decontamination reagents from the SP-HyBRID process solution. They must be conducted at a high efficiency for high performance of the SP-ByBRID process. The $\mathrm{Mn}$ removal is conducted by the conversion of $\mathrm{MnO}_{4}{ }^{-}$in the process solution after the oxidative process into oxide forms by reactions with $\mathrm{N}_{2} \mathrm{H}_{4}$ and the collection of the oxides in the metal filter [13]. In the mock-up test, the Mn removal was conducted at a high efficiency above $82.5 \%$. The Mn removal efficiency was dependent on the injection rate of $\mathrm{N}_{2} \mathrm{H}_{4}$. Mn was effectively removed as the $\mathrm{N}_{2} \mathrm{H}_{4}$ injection rate was lowered because the reactions between $\mathrm{MnO}_{4}{ }^{-}$and $\mathrm{N}_{2} \mathrm{H}_{4}$ were conducted in the circulation system. Diluting $\mathrm{N}_{2} \mathrm{H}_{4} 10$ times using DI water and injecting it at a rate of $1.5-2.0 \mathrm{~mL} / \mathrm{min}$ was the most effective protocol. The $\mathrm{N}_{2} \mathrm{H}_{4}$ is decomposed by the hydroxyl radical generated from the Fenton reaction delineated Equation (1) [13]. This $\mathrm{N}_{2} \mathrm{H}_{4}$ decomposition was also dependent on the injection rate of $\mathrm{H}_{2} \mathrm{O}_{2}$. The proper injection rate of $\mathrm{H}_{2} \mathrm{O}_{2}$ was determined as $10 \mathrm{~mL} / \mathrm{min}$. The theoretical molar ratio of $\mathrm{H}_{2} \mathrm{O}_{2}$ over $\mathrm{N}_{2} \mathrm{H}_{4}$ is 2.0 for the decomposition of $\mathrm{N}_{2} \mathrm{H}_{4}$ using $\mathrm{H}_{2} \mathrm{O}_{2}$ [16]. However, the appropriate molar ratio was 2.75 for the $\mathrm{N}_{2} \mathrm{H}_{4}$ decomposition in the mock-up test. This $\mathrm{N}_{2} \mathrm{H}_{4}$ decomposition was conducted at a low $\mathrm{pH}$ condition where the decomposition is not effective. For this reason, the molar ratio was increased by 2.75. Excess $\mathrm{H}_{2} \mathrm{O}_{2}$ is decomposed into a hydroxyl radical $(\cdot \mathrm{OH})$, as shown in Equation (1), and then converted into $\mathrm{H}_{1.5} \mathrm{O}$ [17]. Thus, excess $\mathrm{H}_{2} \mathrm{O}_{2}$ was not a problem in the next process. In the mock-up test, the $\mathrm{N}_{2} \mathrm{H}_{4}$ remained at a level below $1 \mathrm{ppm}$.

$$
\mathrm{Fe}^{2+}+\mathrm{H}_{2} \mathrm{O}_{2}+\mathrm{H}^{+}=\mathrm{Fe}^{3+}+\left(\cdot \mathrm{OH}+\mathrm{H}_{2} \mathrm{O}\right.
$$

In general, metal oxides in the corrosion oxide layer are converted into ionic forms in a decontamination solution when the oxide layer is dissolved in the solution [18]. 
Thus, concentrations of metal ions in a decontamination solution can be used to understand the dissolution of the corrosion oxide layer during a decontamination process. Figure 7 shows concentrations of metal ions dissolved in each unit process solution during the mock-up test. As seen in Figure 7, as the number of the decontamination cycles increased, the concentrations of metal ions dissolved in each unit process solution tended to increase. In particular, the increase in the concentrations was significant in the second cycle despite the shorter operating time of the first cycle compared to the second cycle. This trend was clearly observed in the dissolution of the $\mathrm{Cr}$ oxide layer on the specimens. It was assumed that the $\mathrm{Cr}$ oxide layer is under the iron oxide layer although it was not characterized in the XRD-patterns in Figure 3 [3,4]. This means that the $\mathrm{Cr}$ oxide dissolution can be lowered during the first cycle because the iron oxide layer was inhibiting the solution contacting the Cr oxide layer, as shown in Figure 7. In the other hand, the $\mathrm{Cr}$ oxide dissolution was significantly improved in the second oxidative process. These results indicate that the simulated oxide layer on the specimen was converted into a form that is easier to dissolve in the first cycle when compared to the initial form. This means that the first cycle is an important pretreatment process for the second cycle, and the first oxidative process conducted at a pH below 2.3 can be an effective pretreatment process for the conversion. For this reason, the operating time of the first oxidative process in the decontamination test of the contaminated RCP shaft was scheduled as about $10 \mathrm{~h}$. Figure 7 also shows that the concentrations of $\mathrm{Cr}$ and $\mathrm{Fe}$ in the process solution after the filter cleaning were increased when compared to those after the 3 rd reductive process. In particular, the concentrations of $\mathrm{Cr}$ in the 1st and 2nd reductive process solutions decreased when compared to those in the 1st and 2nd oxidative process solutions, as shown in Figure 7. These results indicate that some of the $\mathrm{Cr}$ and $\mathrm{Fe}$ ions in the oxidative process solution were converted into an insoluble form and collected in the metal filter during the Mn removal process. This decrease in the metal concentration in the process solution can contribute to improving the dissolution performance of the corrosion oxide layer in the next process. On the other hand, the ionic form of $\mathrm{Ni}$ was maintained in the Mn removal process.

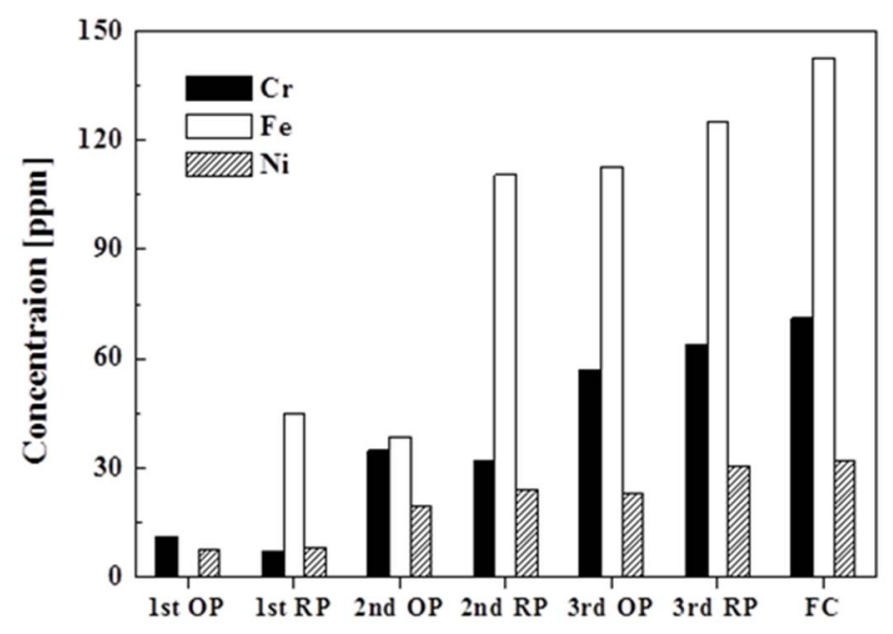

Unit process in the SP-HyBRID process

Figure 7. Concentrations of metal ions dissolved in each unit process solution during the mock-up test (OP: oxidative process, RP: reductive process, FC: filter cleaning).

After the filter cleaning, the specimens mounted on the mockup of the RCP shaft were recovered, and they are shown in Figure 8. The simulated corrosion oxide layer was almost completely removed, as shown in Figure 8. It is thus thought that the detailed conditions of the SP-HyBRID process established by the mock-up test can be applied to decontamination of the contaminated RCP shaft. 


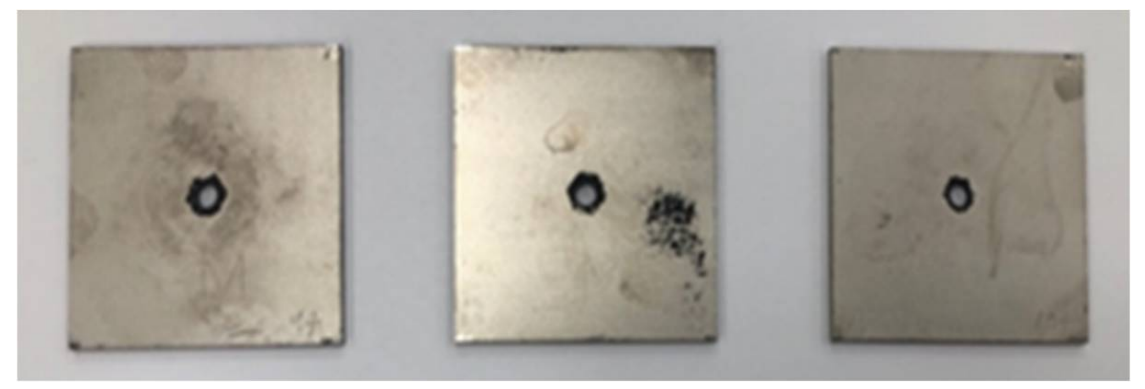

Figure 8. Specimens after the mock-up test.

\subsection{Decontamination of the Contaminated RCP Shaft Head}

Based on the mock-up test results, the decontamination test of the contaminated RCP shaft was conducted with monitoring of the changes in the $\mathrm{pH}$ of the unit process solution. The changes in the $\mathrm{pH}$ of the unit process solutions during the decontamination test showed similar trends to those in the mock-up test, as presented in Figure 6. The Mn removal was performed at a similar efficiency to that obtained in the mock-up test, and the $\mathrm{N}_{2} \mathrm{H}_{4}$ was decomposed and removed at a level of about $0.5 \mathrm{ppm}$. These results indicate that the decontamination test was performed well in accordance with the conditions derived from the mock-up test.

After each cycle, the dose rate of spot A in Figure 4 was measured to evaluate the decontamination performance using the teletector radiation detector, and the results are shown in Figure 9. As presented in Figure 9, most of the radioactive contaminants on the RCP shaft head were removed during the 1 st cycle. The initial dose rate $(1400 \mu \mathrm{Sv} / \mathrm{h})$ was reduced by $67 \mu \mathrm{Sv} / \mathrm{h}$ after the 1 st cycle. It is considered that the long operation time $(10 \mathrm{~h})$ of the 1st cycle oxidative process contributed to this significant reduction of the dose rate. The dose rate was further decreased by $0.8 \mu \mathrm{Sv} / \mathrm{h}$ after the 2 nd cycle, and it was not changed during the 3 rd cycle. This means that the decontamination of the RCP shaft head was completed after the 2 nd cycle. The dose rates after the 2 nd and 3 rd cycles were almost at the same level as the ambient dose rate, and this indicates that the activities on the RCP shaft head were almost completely removed. As seen in Figure 10, photos of the RCP shaft head after each cycle showed similar trends to the decontamination results. The DF was calculated using Equation (2), and it showed a very high value (>1500) $[11,19,20]$.

$$
\mathrm{DF}=\text { Initial dose rate/Final dose rate }
$$

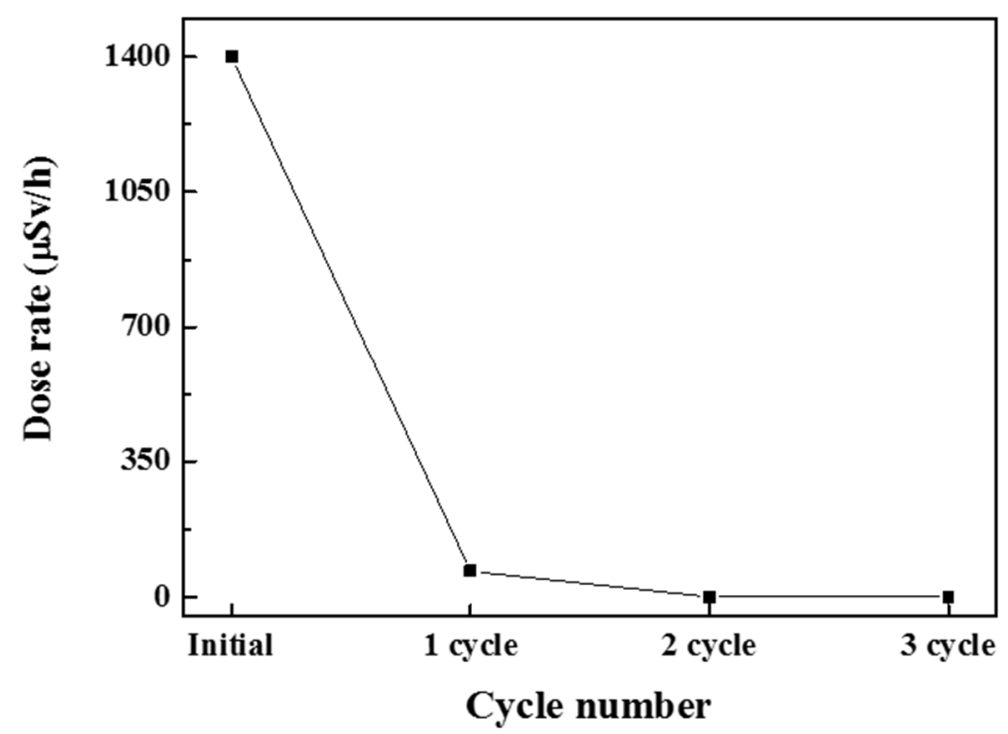

Figure 9. Dose rate of the spot A in Figure 4 after each cycle. 

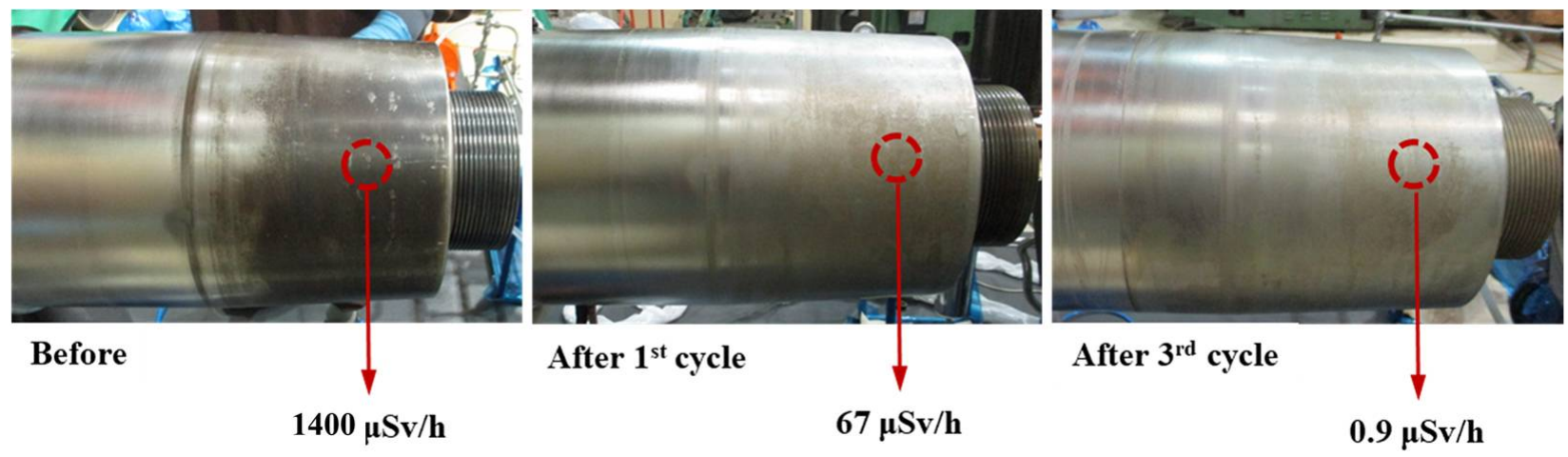

Figure 10. Photos of the RCP shaft head after each cycle.

After completing the filter cleaning, the concentrations of radioactive nuclides in the decontamination wastewater were analyzed using HPGe detector, and the results are provided in Table 3. The removal activity was calculated by using the concentration of radioactive nuclide and volume of wastewater. From this result, the removal amount of radioactive nuclide was calculated from following Equation (3).

$($ Removal amount, $[\mu \mathrm{g}])=($ Removal activity, $[\mathrm{Bq}]) /($ Specific activity $[\mathrm{TBq} / \mathrm{g}]) \times 10^{6}$

Table 3. Concentrations of radioactive nuclides in the wastewater $(30 \mathrm{~L})$ after the decontamination test of the RCP shaft head.

\begin{tabular}{lcccc}
\hline \multicolumn{1}{c}{ Nuclide } & Mn-54 & Co-57 & Co-60 & Zn-65 \\
\hline Concentration $(\mathrm{Bq} / \mathrm{mL})$ & $2.56 \times 10$ & 5.37 & $8.16 \times 10^{2}$ & 4.21 \\
Removal activity $(\mathrm{Bq})$ & $7.68 \times 10^{5}$ & $1.61 \times 10^{5}$ & $2.45 \times 10^{7}$ & $1.26 \times 10^{5}$ \\
Activity fraction $(\%)$ & 3.01 & 0.63 & 95.87 & 0.49 \\
Removal amount $(\mu \mathrm{g})$ & $2.68 \times 10^{-3}$ & $5.16 \times 10^{-4}$ & $5.86 \times 10^{-1}$ & $4.14 \times 10^{-4}$ \\
Mass fraction $(\%)$ & 0.46 & 0.09 & 99.39 & 0.07 \\
Specific activity $(\mathrm{TBq} / \mathrm{g})$ & $2.87 \times 10^{2}$ & $3.12 \times 10^{2}$ & $4.19 \times 10$ & $3.05 \times 10^{2}$ \\
\hline
\end{tabular}

The fractions of activity and mass were derived based on the removal activity and amount. As listed in Table 3, radionuclides such as Mn-54, Co-57, Co-60, and Zn-65 were dissolved from the RCP shaft head, and $2.55 \times 10^{7} \mathrm{~Bq}$ of gamma-emitting activity was removed during the decontamination. The activity fraction of Co-60 was over 95\%. Removal amounts of the radionuclides were calculated using their specific activities, as shown in Table 3, and a total of $0.6 \mu \mathrm{g}$ was removed during the decontamination (Co-60 > 99\%).

Through the above decontamination results, it was confirmed that corrosion oxides containing radionuclides such as Co-60 on the metal surface can be almost completely removed using the SP-HyBRID process. It is thus considered that the SP-HyBRID process as an alternative to commercial decontamination technologies can be effectively applied to the decontamination of RCS in a nuclear facility.

\section{Conclusions}

In this study, the decontamination of the RCP shaft head from a nuclear facility was conducted using the inorganic chemical decontamination process, SP-HyBRID. The contaminated RCP shaft head was perfectly decontaminated in two cycles, and the DF showed a very high value (>1500). It is thus thought that the SP-HyBRID process as an alternative to commercial decontamination technologies using organic chemicals can be effectively applied to the decontamination of RCS in nuclear facilities.

Author Contributions: Conceptualization, H.-C.E.; methodology, H.-C.E., W.-K.C., S.-Y.P. and N.O.C.; formal analysis, H.-C.E., K.-C.K. and S.-G.A.; investigation, H.-C.E.; resources, K.-C.K. and 
S.-G.A.; writing-original draft preparation, H.-C.E.; writing-review and editing, H.-C.E. and N.-O.C.; supervision, S.-B.K.; project administration, S.-B.K. and B.-K.S.; funding acquisition, B.-K.S. All authors have read and agreed to the published version of the manuscript.

Funding: This research was supported by National Research Foundation of Korea (NRF), which is funded by Ministry of Science, ICT and Future Planning (MSIP) of Republic of Korea, grant number NRF-2017M2A8A5015144.

Institutional Review Board Statement: Not applicable.

Informed Consent Statement: Not applicable.

Data Availability Statement: Not applicable.

Conflicts of Interest: The authors declare no conflict of interest.

\section{References}

1. Kim, S.; Park, S.; Cho, W.; Won, H.; Park, J.; Seo, B. Magnetic dissolution of copper catalyzed reductive decontamination. J. Nucl. Fuel Cycle Waste Technol. 2018, 16, 421-429. [CrossRef]

2. Flambard, J.; Carrette, F.; Monchy-Leroy, C.; Andrieu, E.; Laffont, L. Influence of the transient conditions on release of corrosion products and oxidation of alloy 690 tubes during pressurized water reactor restart after stream generators replacement. J. Nucl. Mater. 2021, 543, 152562. [CrossRef]

3. McGrandy, J.; Duff, J.; Stevens, N.; Cioncolini, A.; Curioni, M.; Banks, A.; Scenini, F. Development of a microfluidic setup to study the corrosion product deposition in accelerated flow regions. npj Mater. Degrad. 2017, 1, 21. [CrossRef]

4. Rufus, A.L.; Sathyaseelan, V.S.; Pavithra, E.; Velmurugan, S. Dissolution of corrosion product oxides relevant to nuclear power plants in formulations containing chromous complexes. J. Nucl. Mater. 2019, 520, 121-130. [CrossRef]

5. Varga, K.; Hirschberg, G.; Nemeth, Z.; Myburg, G.; Schunk, J.; Tilky, P. Accumulation of radioactive corrosion products on steel surfaces of VVER-type nuclear reactors. II. ${ }^{60}$ Co. J. Nucl. Mater. 2001, 298, 231-238. [CrossRef]

6. Rufus, A.L.; Velmurugan, S.; Sathyaseelan, V.S.; Narasimhan, S.V. Comparative study of nitrile triacetic acid (NTA) and EDTA as formulation constituents for the chemical decontamination of primary coolant systems of nuclear power plants. Prog. Nucl. Energy 2004, 44, 13-31. [CrossRef]

7. Wood, C.J. A review of the application of chemical decontamination technology in the United States. Prog. Nucl. Energy 1990, 23, 35-80. [CrossRef]

8. Bradbury, D. Review of decontamination technology development. In Proceedings of the International Conference of Water Chemistry Nuclear Reactor System 8 Organized by the British Nuclear Energy Society, Bournemouth, UK, 22-26 October 2000.

9. Riess, R. Decontamination and Steam Generator Chemical Cleaning; Advanced Nuclear Technology International: Skultuna, Sweden, 2009.

10. Topf, C.; Sempere-Belda, L. Aqueous, in situ primary circuit decontamination. Nucl. Eng. Int. 2014, 59, $16-18$.

11. Topf, C. Full decontamination (FSD) with the CORD family prior to decommissioning-Experiences at the German NPP Obrigheim 2007. In Proceedings of the International Youth Nuclear Congress, Interlaken, Switzerland, 20-26 September 2008.

12. Choi, W.; Won, H.; Chong, J.; Park, S.; Kim, S.; Yoon, I.; Moon, J.; Choi, J.; An, B.; Choi, M.; et al. Development of Advanced Decontamination Technology for Nuclear Facilities; KAERI/RR-4230/2016; Korea Atomic Energy Research Institute. 2017. Available online: https://inis.iaea.org/collection/NCLCollectionStore/_Public/49/108/49108305.pdf?r=1 (accessed on 22 September 2021).

13. Eun, H.; Park, S.; Choi, W.; Kim, S.; Won, H.; Chang, N.; Lee, S.; Park, J.; Seo, B.; Kim, K. A waste-minimized chemical decontamination process for the decontamination of a nuclear reactor coolant system. J. Radioanal. Nucl. Chem. 2020, 326, 665-674. [CrossRef]

14. Jung, J.; Eun, H.; Park, S.; Park, J.; Chang, N.; Kim, S.; Seo, B.; Park, S. A study on the removal of impurities in a SP-HyBRID decontamination wastewater of the primary coolant system in a pressurized water reactor. J. Radioanal. Nucl. Chem. 2018, 318, 1339-1345. [CrossRef]

15. Eun, H.; Jung, J.; Park, S.; Park, J.; Chang, N.; Won, H.; Sim, J.; Kim, S.; Seo, B. Removal and decomposition of impurities in wastewater from the HyBRID decontamination process of the primary system in a nuclear power plant. J. Nucl. Fuel Cycle Waste Technol. 2019, 17, 429-435. [CrossRef]

16. Rao, L.T.; Dubey, S.K.; Javed, A.; Goel, S. Development of mebraneless paper-pencil microfluidic hydrazine fuel cell. Electroanalysis 2020, 32, 2581-2588.

17. Laat, J.; Le, G.; Legube, B. A comparative study of the effects of chloride, sulfate and nitrate ions on the rates of decomposition of $\mathrm{H}_{2} \mathrm{O}_{2}$ and organic compounds by $\mathrm{Fe}(\mathrm{II}) / \mathrm{H}_{2} \mathrm{O}_{2}$ and $\mathrm{Fe}(\mathrm{III}) / \mathrm{H}_{2} \mathrm{O}_{2}$. Chemosphere 2004, 55, 715-723. [CrossRef] [PubMed]

18. Senanayake, G.; Das, G.K.; Lange, A.; Li, J.; Robinson, D. Reductive atmospheric acid leaching of lateritic smectitie/nontronite ores in $\mathrm{H}_{2} \mathrm{SO}_{4} / \mathrm{Cu}(\mathrm{II}) / \mathrm{SO}_{2}$ solutions. Hydrometallurgy 2015, 152, 44-54. [CrossRef]

19. Song, J.; Jung, M.; Lee, S. A study on the applicability for primary system decontamination through analysis on NPP decommission technology and international experience. J. Nucl. Fuel Cycle Waste Technol. 2016, 14, 45-55. [CrossRef]

20. Park, G.; Kim, C. Chemical decontamination design for NPP decommissioning and considerations on its methodology. J. Nucl. Fuel Cycle Waste Technol. 2015, 13, 187-199. [CrossRef] 